\title{
Solitary pleural myeloma diagnosed by semi-rigid thoracoscopy: A case report and literature review
}

\author{
JIN-SHENG OUYANG ${ }^{1}$, YU-PING LI ${ }^{1}$, PENG LI $^{2}$, MIN YE ${ }^{1}$, JUN-RU YE ${ }^{1}$, \\ BEI-BEI WANG ${ }^{1}$, YING ZHOU ${ }^{1}$ and CHENG-SHUI CHEN ${ }^{1}$ \\ Departments of ${ }^{1}$ Respiratory Medicine and ${ }^{2}$ Pathology, The First Affiliated Hospital of Wenzhou Medical University, \\ Wenzhou, Zhejiang 325000, P.R. China
}

Received January 26, 2016; Accepted August 1, 2016

DOI: $10.3892 /$ mco.2016.1000

\begin{abstract}
Multiple myeloma (MM) is characterized by abnormal proliferation of neoplastic plasma cells. Pleural effusion as an initial presentation of this disease is rare, as is true pleural myeloma. We herein present a case of solitary pleural myelomatous lesion in a 70-year-old male patient diagnosed by pleural biopsy via semi-rigid thoracoscopy followed by histopathological examination. Furthermore, a review of the related English literature identified 22 cases of pleural myeloma, only 3 of which were diagnosed by video-assisted thoracoscopy. To the best of our knowledge, this is the first reported case of a solitary pleural myelomatous lesion diagnosed by pleural biopsy via semi-rigid thoracoscopy. Patients with MM with pleural involvement, including the present case, appear to have a short survival despite aggressive treatment. Our patient received chemotherapy with bortezomib, epiadriamycin and dexamethasone; however, he deteriorated rapidly after one cycle of chemotherapy and succumbed to the disease 8 weeks after the initial presentation. According to our experience, semi-rigid thoracoscopy is an effective and safe method for obtaining a pleural specimen for histopathological evaluation.
\end{abstract}

\section{Introduction}

Multiple myeloma (MM) is a hematological malignancy that primarily affects elderly individuals. The clinical manifestations of MM, collectively referred to as 'CRAB', include hypercalcemia, renal insufficiency, anaemia and bony lesions, caused by either direct infiltration by neoplastic plasma cells

Correspondence to: Dr Yu-Ping Li, Department of Respiratory Medicine, The First Affiliated Hospital of Wenzhou Medical University, 2 Fuxue Alley, Ouhai, Wenzhou, Zhejiang 325000, P.R. China

E-mail: liypwzh@126.com

Abbreviations: MM, multiple myeloma; MPE, myelomatous pleural effusion; NL, normal limit; CT, computed tomography; VATS, video-assisted thoracoscopy

Key words: multiple myeloma, plasma cells, pleural effusion, thoracoscopy or deposition of monoclonal immunoglobulins (Ig), particularly light chains. Myelomatous pleural effusion (MPE) is an uncommon manifestation, with only a few cases reported to date (1). Patients with MPE often have advanced-stage disease and poor prognosis, despite aggressive treatment. We herein present a case of of MPE diagnosed via semi-rigid thoracoscopy in a patient with $\operatorname{Ig} \mathrm{A}-\lambda \mathrm{MM}$, and a review of the current literature on clinical manifestations, laboratory examinations and diagnosis of MPE.

\section{Case report}

A 70-year-old male patient presented at The First Affiliated Hospital of Wenzhou Medical University (Wenzhou, China) with a 1-week history of cough and exertional dyspnea with no fever, chest pain, purulent sputum and hemoptysis. The patient was a smoker with $>20$ pack-years, but his medical, social and family history were otherwise unremarkable. On physical examination, the patient appeared pale, with decreased breath sounds and dullness on percussion over the left posterior thorax. The laboratory findings were as follows: White blood cell count, 3.9x10\% / (50.9\% neutrophils, 32.7\% lymphocytes, and $13.5 \%$ monocytes, normal basophils and eosinophils); erythrocyte count, 2.7×10 12/1; hemoglobin, $81 \mathrm{~g} / \mathrm{l}$; platelet count, $180 \times 10^{9} / 1$; total protein, $85.5 \mathrm{~g} / 1$; albumin, $31.8 \mathrm{~g} / \mathrm{l}$; globulin, $53.7 \mathrm{~g} / \mathrm{l}$; serum calcium, $3.6 \mathrm{mmol} / 1$ [normal limit (NL): 2.1-2.6 mmol/1]; serum creatinine, $180 \mu \mathrm{mol} / 1$ (NL: 44-97 $\mu \mathrm{mol} / \mathrm{l}$ ); urea nitrogen, $8.7 \mathrm{~mol} / \mathrm{l}$; C-reactive protein, $30.5 \mathrm{mg} / \mathrm{l}$; lactate dehydrogenase (LDH), $364.0 \mu / 1$; $\beta_{2}$-microglobulin, $21.1 \mu \mathrm{g} / \mathrm{ml}$ (NL: 0.9-2.7 $\mu \mathrm{g} / \mathrm{ml}$ ); serum $\kappa$ light chain, $3.4 \mathrm{~g} / \mathrm{l}$ (NL: 6.3-13.5 g/1); serum $\lambda$ light chain, $28.3 \mathrm{~g} / 1$ (NL: 3.1-7.2 g/l); serum IgA, $24.3 \mathrm{~g} / 1$; IgM, $153.00 \mathrm{mg} / \mathrm{l}$; $\mathrm{IgG}, 4.4 \mathrm{~g} / \mathrm{l}$; and $\operatorname{IgM}, 0.43 \mathrm{~g} / \mathrm{l}$; the $\operatorname{IgE}$ and $\mathrm{IgD}$ levels were normal. Carcinoembryonic antigen (CEA), carbohydrate antigen 19-9 and brain natriuretic peptide levels were within normal limits, and the T-SPOT ${ }^{\circledR}$ tuberculosis test was negative. Computed tomography (CT) revealed left pleural effusion and atelectasis of the lower lobe of the left lung (Fig. 1). Fiberoptic bronchoscopy revealed no endobronchial lesions. The patient underwent thoracentesis and the pleural fluid was highly cellular, with a nucleated cell count of $1.7 \times 10^{9} / 1(42 \%$ mononuclear cells), and contained total protein at $46.1 \mathrm{~g} / 1$, $\mathrm{LDH}$ at 193.0 U/1, adenosine deaminase at 20.0 U/1 and CEA 

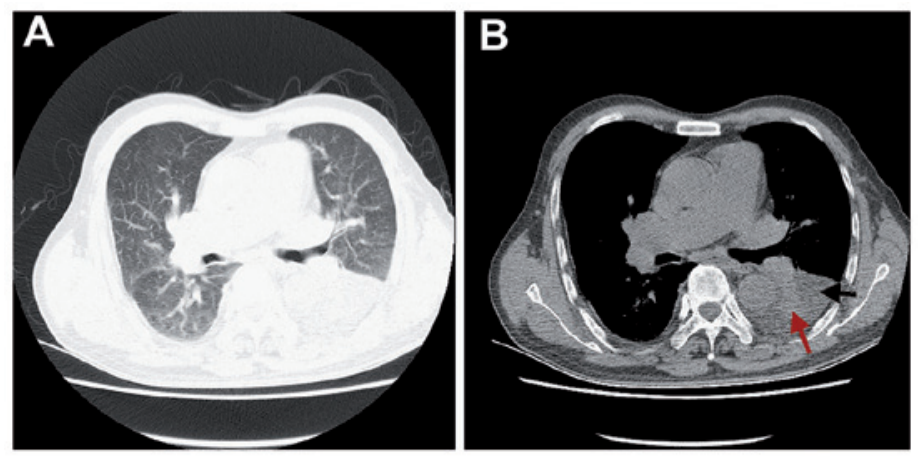

Figure 1. Computed tomography scans of the chest. (A) Lung window and (B) mediastinal window showing left pleural effusion (black arrow) and compressive atelectasis of the lung (red arrow).
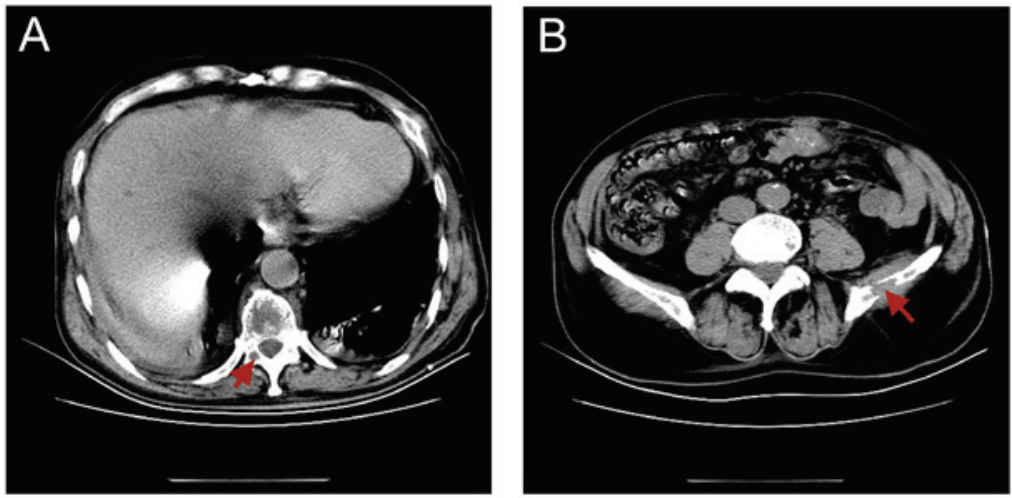

Figure 2. Abdominal computed tomography scans showing lytic lesions of (A) of a thoracic vertebra and (B) the innominate bone (arrows).
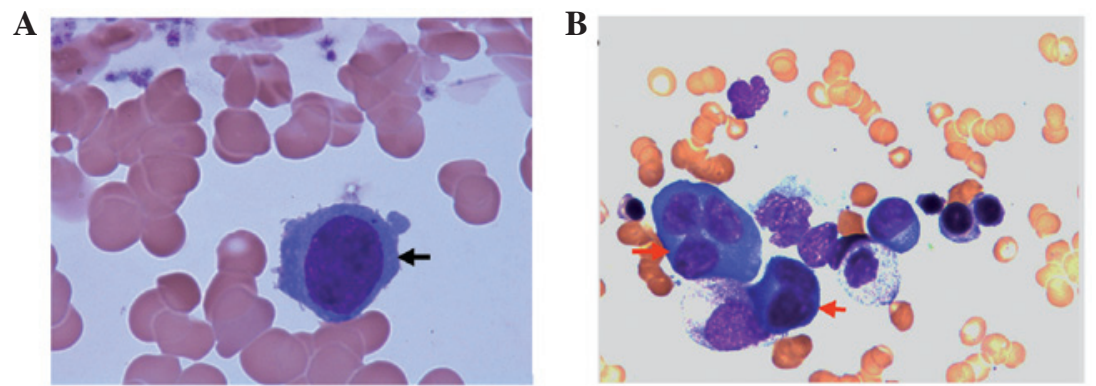

Figure 3. Cytology of the bone marrow. (A) Normal plasma cell (arrow). (B) Malignant plasma cells were detected in the bone marrow, characterized by large, eccentrically placed, pleomorphic nuclei with prominent nucleoli (arrows). Wright-Giemsa stain; magnification, x400.

at $1.5 \mu \mathrm{g} / \mathrm{l}$; thus, the effusion was considered as exudative according to the Light criteria (2). Malignant cells were not found in the pleural fluid. Immune fixation electrophoresis of the blood revealed IgA- $\lambda$-type monoclonal immunoglobulin. The patient underwent bone marrow aspiration biopsy twice. The first bone marrow biopsy showed no significant abnormalities (Fig. 3A), while the second revealed a mildly hypercellular marrow with $13 \%$ plasma cells (Fig. 3B). Semi-rigid thoracoscopy was performed, which revealed a solitary pleural nodule sized $\sim 1 \mathrm{x} 0.8 \mathrm{~cm}$ on the parietal pleura (Fig. 4). Histopathological evaluation of the biopsied nodule revealed sheets of neoplastic plasma cells, which were positive for CD38 and multiple myeloma oncogene 1 (MUM1), with $\lambda$ light chain restriction and a Ki-67 index of 50\% (Fig. 5). The patient was diagnosed with IgA- $\lambda$-type MM with pleural involvement, based on the

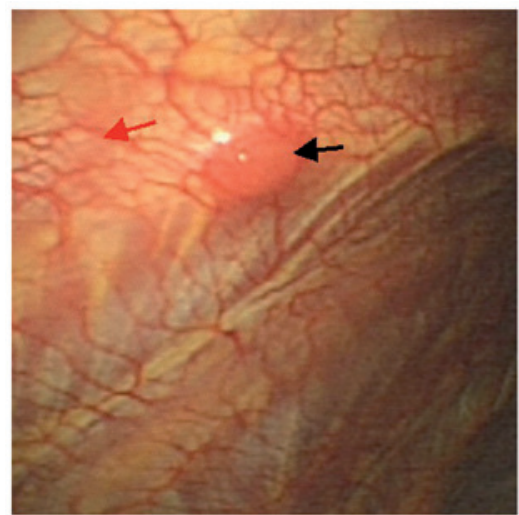

Figure 4. View of the left pleura on semi-rigid thoracoscopy, showing a solitary nodule on the parietal pleural surface (black arrow) and pleural congestion (red arrow). 

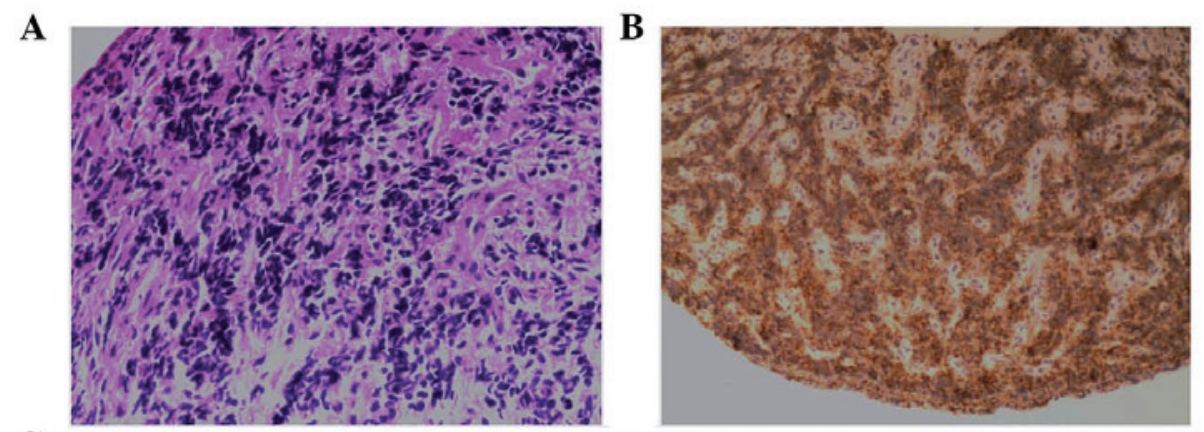

C
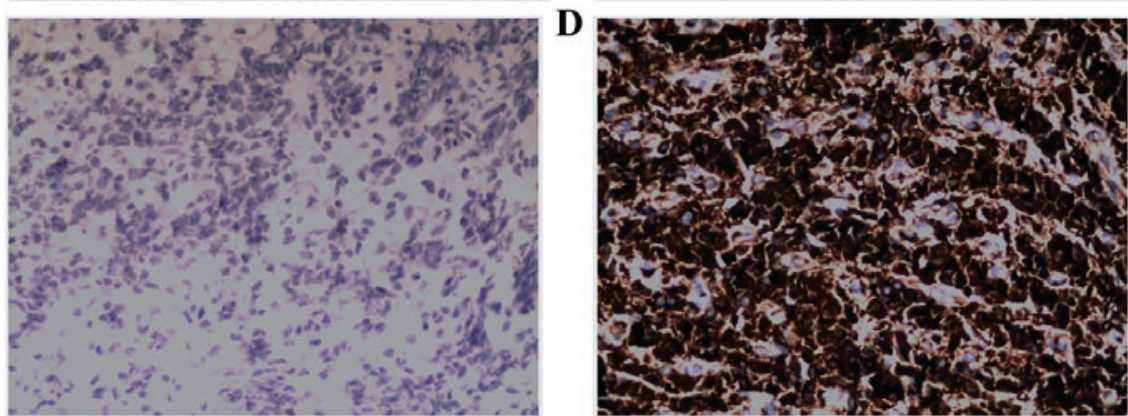

E
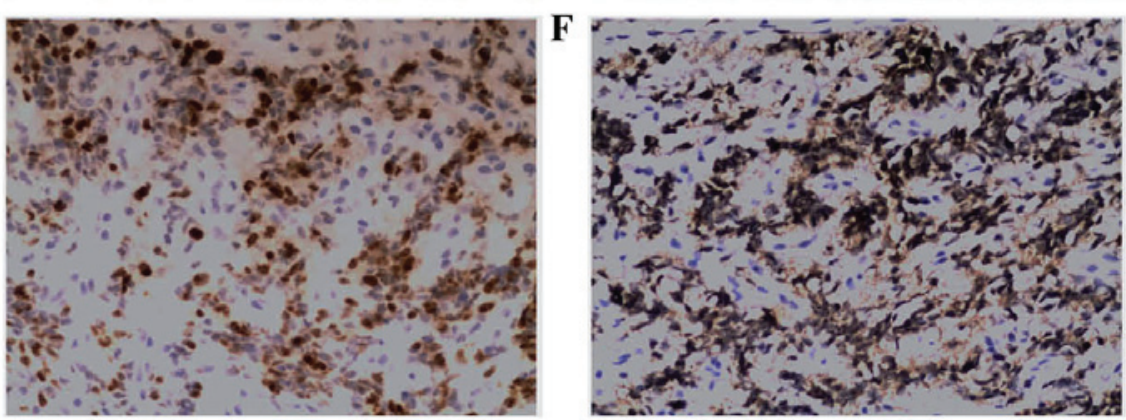

Figure 5. Histopathology and immunohistochemistry images of the pleural biopsy specimen (magnification, x200). (A) Hematoxylin and eosin staining revealed abnormal proliferation of plasma cells. The immunohistochemical staining results were as follows: (B) CD38 ${ }^{+},(\mathrm{C}) \kappa^{-},(\mathrm{D}) \lambda^{+},(\mathrm{E}) \mathrm{Ki}-67^{+}(>50 \%)$ and (F) multiple myeloma oncogene 1 (MUM1) ${ }^{+}$. Positive staining for CD38 is characteristic for malignant plasma cell disease. The myeloma-specific oncogene MUM1 is a key regulator of several steps in lymphoid, myeloid and dendritic cell differentiation and maturation. $\kappa$ and $\lambda$, light chains in multiple myeloma.

clinical manifestations, laboratory examinations, radiographic findings and the results of bone marrow and pleural biopsies. The patient received chemotherapy with bortezomib, epiadriamycin and dexamethasone; however, he deteriorated rapidly after one cycle of chemotherapy and succumbed to the disease 8 weeks after the initial presentation.

Written informed consent was obtained from the patient regarding the publication of this case report and any accompanying images.

\section{Discussion}

As a hematopoietic malignancy, MM primarily affects the bone marrow, but may also involve extramedullary tissue. The characteristic clinical manifestations of MM, collectively referred to as 'CRAB', include hypercalcemia, renal failure, anemia and bone lesions. MPE is an uncommon manifestation, occurring in $\sim 6 \%$ of patients with MM (1). Our patient presented with the typical 'CRAB' signs and symptoms in addition to a pleural myelomatous lesion. The possible etiological factors for pleural effusion include congestive heart failure secondary to amyloidosis, chronic renal failure, nephritic syndrome secondary to renal tubular infiltration with paraprotein and development of glomerular damage, direct infiltration of pleural fluid from adjacent tissues, hypoalbuminemia, pulmonary embolism, secondary neoplasm, lymphatic drainage obstruction by tumor infiltration, infection and pleural myelomatous involvement (3). It has been reported that $80 \%$ of MPE cases are related to IgA MM (4); our patient was also IgA type. In the present case, the unilateral exudative effusion was mainly attributed to a localized pleural myelomatous lesion. Chemotherapy is the mainstay of therapy for pleural myeloma, despite the low response rate and short survival time.

An English literature search for related studies between 1990 and 2015 was conducted through PubMed, using the search criteria ('pleural effusion' and 'multiple myeloma') or 'myelomatous pleural effusions', which yielded 152 candidate articles. Based on the inclusion criteria (pleural myelomatous involvement confirmed by cytological analysis of pleural effusion or histopathological evaluation of pleural biopsy specimens), a total of 22 cases were included in the final review and analysis. The patient characteristics, including general information, laboratory test results, diagnostic methods and clinical outcomes, were retrospectively reviewed and are summarized in Table I. The patient age ranged from 40 to 83 years, with 
Table I. Reported cases of pleural myeloma.

\begin{tabular}{|c|c|c|c|c|c|c|c|c|}
\hline First author (Refs.) & Year & Age/gender & Ig type & EMI & Osteolysis & Pathology & Thoracoscopy & $\begin{array}{l}\text { Survival }{ }^{\mathrm{a}} \\
\text { (months) }^{\text {S }}\end{array}$ \\
\hline Jiang (5) & 2015 & 78/ND & $\operatorname{IgD}$ & No & Yes & CPE & No & ND \\
\hline Suwatanapongched (6) & 2014 & 76/M & $\operatorname{IgG}-\lambda$ & No & Yes & CPE & No & 1 \\
\hline Zhang (7) & 2014 & $53 / \mathrm{M}$ & IgG- $\kappa$ & No & No & Pleural biopsy & VATS & ND \\
\hline $\mathrm{Xu}(8)$ & 2013 & $45 / M$ & Negative & No & Yes & Pleural biopsy & No & 12 \\
\hline Chim (9) & 2013 & $56 / \mathrm{M}$ & $\operatorname{IgG}-\lambda$ & No & No & ND & No & 5 \\
\hline Oudart (3) & 2012 & $62 / \mathrm{F}$ & IgG- $\kappa$ & ND & ND & CPE & No & ND \\
\hline Klanova (10) & 2012 & $43 / \mathrm{F}$ & $\operatorname{IgG-\kappa }$ & Yes $^{b}$ & Yes & CPE & No & 12 \\
\hline Keklik (11) & 2012 & $52 / \mathrm{M}$ & IgG-к & No & Yes & CPE & No & ND \\
\hline Al-Farsi (12) & 2010 & $56 / \mathrm{M}$ & $\operatorname{IgG-\kappa }$ & No & Yes & CPE & No & 6 \\
\hline Huang (13) & 2010 & $67 / \mathrm{F}$ & $\operatorname{Ig} A-\lambda$ & NG & ND & $\mathrm{CPE}$ & No & ND \\
\hline Malhotra (14) & 2010 & $50 / \mathrm{M}$ & ND & NG & ND & CPE & No & 2 \\
\hline Ghoshal (15) & 2010 & $61 / \mathrm{F}$ & ND & NG & Yes & Pleural biopsy & No & ND \\
\hline Nakazato (16) & 2009 & $74 / \mathrm{M}$ & $\operatorname{IgG}-\kappa$ & Yes $^{\mathrm{b}}$ & Yes & CPE & No & 8 \\
\hline Neuman (17) & 2009 & 47/M & ND & ND & Yes & CPE & No & ND \\
\hline Chang (18) & 2009 & $83 / \mathrm{F}$ & $\operatorname{IgD}-\lambda$ & ND & No & CPE & No & 2 \\
\hline Yokoyama (19) & 2008 & $58 / \mathrm{M}$ & $\operatorname{IgD}$ & Yes $^{\mathrm{b}}$ & NG & Pleural biopsy & No & 3 \\
\hline $\operatorname{Kim}(20)$ & 2008 & $76 / \mathrm{F}$ & $\operatorname{Ig} \mathrm{A}-\lambda$ & ND & Yes & CPE & No & 1 \\
\hline Dhingra (21) & 2007 & $40 / \mathrm{M}$ & $\mathrm{IgG}$ & ND & Yes & $\mathrm{CPE}$ & No & ND \\
\hline Inoue (22) & 2005 & $51 / \mathrm{F}$ & $\operatorname{IgG}-\lambda$ & Yes $^{b}$ & ND & Pleural biopsy & VATS & 10 \\
\hline $\operatorname{Kim}(23)$ & 2000 & $61 / \mathrm{F}$ & $\operatorname{IgG}-\lambda$ & ND & ND & Pleural biopsy & No & ND \\
\hline Rodríguez (4) & 1994 & $51 / \mathrm{M}$ & $\operatorname{IgA}-\kappa$ & ND & Yes & CPE & No & 11 \\
\hline Makino (24) & 1992 & $73 / \mathrm{F}$ & $\mathrm{IgG}$ & ND & No & CPE & No & ND \\
\hline Present case & 2015 & $70 / \mathrm{M}$ & $\operatorname{Ig} A-\lambda$ & ND & Yes & Pleural biopsy & SRTS & 8 \\
\hline
\end{tabular}

${ }^{a}$ After presentation with pleural effusion. ${ }^{b}$ Lymphadenopathy. EMI, extramedullary involvement; ND, not defined; CPE, cytology of pleural effusion; M, male; F, female; PM, pleural myeloma; PE, pleural effusion; VATS, video-assisted thoracoscopy sampling; Ig, immunoglobulin; SRTS, semi-rigid thoracoscopy.

a mean of 60 years and a slight male predominance. The diagnosis was made by cytological analysis of the pleural effusion in 15 cases; pleural biopsy specimens were examined in 7 patients, including 3 undergoing video-assisted thoracoscopy sampling (VATS) and 1 undergoing semi-rigid thoracoscopy (present case). The diagnostic method for pleural myeloma was not specified in the remaining case. All patients with pleural involvement had a short survival (ranging from 4 weeks to 12 months) after presentation with pleural effusion. The literature review revealed that $\mathrm{MM}$ with pleural involvement most commonly affects older ( $\geq 50$ years) and elderly patients ( $\geq 65$ years) and is associated with a poor prognosis.

In the previously reported cases reviewed herein, pleural myeloma was identified by pleural effusion cytology or/and histological examination of pleural biopsy specimens, despite the advantages of thoracoscopy, or open and multiple-site biopsy. However, a localized pleural myelomatous lesion is difficult to detect on CT or ultrasonography, which hampers image-guided direct biopsy of the lesion. With the advances in thoracoscopic techniques, open and multiple-site pleural biopsy may be performed by VATS or semi-rigid thoracoscopy. These procedures may improve the diagnostic rate in patients with pleural lesions of unknown etiology. However, thoracoscopy is rarely considered as a feasible option for identifying the etiology of pleural effusion in patients with MM. In selected patients, semi-rigid thoracoscopy may be superior to VATS in terms of safety and cost-effectiveness. As semi-rigid thoracoscopy may be successfully performed under local anesthesia and intravenous sedation, the majority of patients with mild or moderate cardiopulmonary dysfunction may safely undergo this procedure, while they would not be eligible for VATS due to the risks associated with general anesthesia. Our patient underwent semi-rigid thoracoscopy with biopsy of a small solitary nodule on the left parietal pleura, which was diagnosed as a myelomatous lesion. To the best of our knowledge, this was the first report of a solitary pleural myelomatous lesion diagnosed by pleural biopsy via semi-rigid thoracoscopy. Semi-rigid thoracoscopy may be successfully performed by pulmonologists under local anesthesia. The procedure appears to be safer, more cost-effective and comfortable for patients compared with VATS.

In summary, we reported a case of solitary pleural myelomatous nodule diagnosed by semi-rigid thoracoscopy and pleural histopathology. Although MPE is uncommon, MM should be considered in patients with pleural effusion of unknown etiology. Semi-rigid thoracoscopy appears to be a feasible option for diagnosing pleural myeloma in the era of precision medicine. 


\section{References}

1. Kintzer JS Jr, Rosenow EC III and Kyle RA: Thoracic and pulmonary abnormalities in multiple myeloma. A review of 958 cases. Arch Intern Med 138: 727-730, 1978.

2. Light RW: The Light criteria: The beginning and why they are useful 40 years later. Clin Chest Med 34: 21-26, 2013.

3. OudartJB,MaquartFX,SemoumaO,Lauer M,Arthuis-DemoulinP and Ramont L: Pleural effusion in a patient with multiple myeloma. Clin Chem 58: 672-674, 2012.

4. Rodríguez JN, Pereira A, Martinez JC, Conde J and Pujol E: Pleural effusion in multiple myeloma. Chest 105: 622-624, 1994.

5. Jiang AG, Yang YT, Gao XY and Lu HY: Bilateral pleural effusion as an initial manifestation of multiple myeloma: A case report and literature review. Exp Ther Med 9: 1040-1042, 2015.

6. Suwatanapongched T, Pornsuriyasak P, Kanoksil W, Morasert T and Virayavanich W: A 76-year-old man with anemia, bone pain, and progressive dyspnea. Diagnosis: Bilateral myelomatous pleural effusions with extramedullary plasmacytomas. Chest 145 913-918, 2014.

7. Zhang LL, Li YY, Hu CP and Yang HP: Myelomatous pleural effusion as an initial sign of multiple myeloma-a case report and review of literature. J Thorac Dis 6: E152-E159, 2014.

8. Xu XL, Shen YH, Shen Q and Zhou JY: A case of bilateral pleural effusion as the first sign of multiple myeloma. Eur J Med Res 18: 7, 2013.

9. Chim CS and Ma ES: Survival of $>20$ years in a myeloma patient with an unusual combination of $\mathrm{t}(14 ; 16)$ and hyperdiploidy: A case report. Oncol Lett 6: 1663-1664, 2013.

10. Klanova M, Klener P, Trneny M, Straub J and Spicka I: Intrapleural bortezomib for the therapy of myelomatous pleural effusion: A case report. Case Reports Immunol 2012: 978479, 2012.

11. Keklik M, Sivgin S, Pala C, Eroglu C, Akyol G, Kaynar L, Koker MY, Camlica D, Unal A, Cetin M and Eser B: Flow cytometry method as a diagnostic tool for pleural fluid involvement in a patient with multiple myeloma. Mediterr J Hematol Infect Dis 4: e2012063, 2012.

12. Al-Farsi K, Al-Haddabi I, Al-Riyami N, Al-Sukaiti R and Al-Kindi S: Myelomatous Pleural Effusion: Case report and review of the literature. Sultan Qaboos Univ Med J 11: 259-264, 2011.
13. Huang TC and Chao TY: Myelomatous pleural effusion. QJM 103: 705-706, 2010.

14. Malhotra KP, Agrawal V and Prasad N: Myelomatous pleural effusion: A diagnostic challenge. Indian J Cancer 47: 351-352, 2010.

15. Ghoshal AG, Sarkar S, Majumder A and Chakrabarti S: Unilateral massive pleural effusion: A presentation of unsuspected multiple myeloma. Indian J Hematol Blood Transfus 26: 62-64, 2010.

16. Nakazato T, Suzuki K, Mihara A, Sanada Y and Kakimoto T: Refractory plasmablastic type myeloma with multiple extramedullary plasmacytomas and massive myelomatous effusion: Remarkable response with a combination of thalidomide and dexamethasone. Intern Med 48: 1827-1832, 2009.

17. Neuman G and Denekamp Y: Dyspnea and pleural effusion as presenting clinical manifestations of multiple myeloma. Isr Med Assoc J 11: 118-119, 2009.

18. Chang H, Chou WC, Lee SY, Huang JY and Hung YH: Myelomatous pleural effusion in a patient with plasmablastic myeloma: A case report. Diagn Cytopathol 37: 205-207, 2009.

19. Yokoyama T, Tanaka A, Kato S and Aizawa H: Multiple myeloma presenting initially with pleural effusion and a unique paraspinal tumor in the thorax. Intern Med 47: 1917-1920, 2008.

20. Kim YJ, Kim SJ, Min K, Kim HY, Kim HJ, Lee YK and Zang DY: Multiple myeloma with myelomatous pleural effusion: A case report and review of the literature. Acta Haematol 120: 108-111, 2008.

21. Dhingra KK, Singhal N, Nigam S and Jain S: Unsuspected multiples myeloma presenting as bilateral pleural effusion-a cytological diagnosis. Cytojournal 4: 17, 2007.

22. Inoue Y, Chua K, McClure RF, Jimenez MC, Gocke CD, Badros AZ and Takebe N: Multiple myeloma presenting initially as a solitary pleural effusion later complicated by malignant plasmacytic ascites. Leuk Res 29: 715-718, 2005.

23. Kim YM, Lee KK, Oh HS, Park SK, Won JH, Hong DS, Park HS, Park JS and Lee DW: Myelomatous effusion with poor response to chemotherapy. J Korean Med Sci 15: 243-246, 2000.

24. Makino S, Yamahara S, Nagake Y and Kamura J: Bence-Jones myeloma with pleural effusion: Response to alpha-interferon and combined chemotherapy. Intern Med 31: 617-621, 1992. 